\title{
Observações sobre domiciliação de mosquitos Culex (Melanoconion), em ambiente com acentuadas modificações antrópicas*
}

\author{
Domiciliation of Culex (Melanoconion) mosquitoes in man-made deeply \\ modified environment
}

\author{
Oswaldo Paulo Forattini"*, Almério de Castro Gomes**, Iná Kakitani"*, Daniel Marucci"*
}

\begin{abstract}
FORATTINI, O.P. et al. Observações sobre domiciliação de mosquitos Culex (Melanoconion) em ambiente com acentuadas modificações antrópicas. Rev. Saúde públ., S. Paulo, 25: 257-66, 1991. Estudam-se alguns aspectos do comportamento de espécies de Culex (Melanoconion) em ambiente antrópico intensamente modificado. Foram realizadas coletas mensais de adultos, concomitantes e levadas a efeito no peridomicílio, em área aberta e em área coberta por vegetação de segunda formação. Foram focalizadas as espécies dominantes e representadas por $C x$. delpontei, $C x$. ocossa, $C x$. ribeirensis, $C x$. sacchettae e $C x$. taeniopus. No peridomicílio, destacam-se pela regularidade de sua presença, $C x$. ribeirensis e $C x$. sacchettae, incluindo apreciável comparecimento às coletas com isca humana ali realizadas. A época de maior rendimento das capturas correspondeu ao primeiro trimestre, em especial modo, ao mês de março. Aliado a esse aspecto, $C x$. ribeirensis e $C x$. sacchettae revelaram apreciável frequiência à isca humana. Em relação a esta, o menor comparecimento foi apresentado por $C x$. delpontei e $C x$. ocossa. Quanto a $C x$. taeniopus, compareceu de maneira um tanto irregular e em númeto geralmente inferior ao dos demais. As observações evidenciaram curva de atividade aumentando rapidamente por ocasião do início da noite e mantendo-se durante todo o periodo notumo, apresentada por $C x$. ribeirensis, $C x$. sacchettae e $C x$. taeniopus. O outro tipo de curva foi observado com $C x$. delpontei e $C x$. ocossa, com aumento gradual na primeira metade da noite, alcançando o máximo ao redor da meia-noite, e declinando sensivelmente na segunda metade do período. As coletas de formas imaturas permitiram evidenciar criadouros de $C x$. delpontei em cursos de água de porte médio ou grande, e associados à vegetação aquática flutuante. São feitas considerações de ordem ecologica passíveis de interpretar esses comportamentos de interesse epidemiológico.
\end{abstract}

Descritores: Mosquitos. Culex (Melanoconion). Culex ribeirensis. Culex sacchettae. Culex delpontei. Culex taeniopus. Domiciliação.

\section{Introduçåo}

Por ocasiāo de pesquisas anteriormente realizadas na região sudeste, Estado de São Paulo, pôde-se registrar alguns aspectos potencialmente significantes sob o ponto de vista epidemiológico, e concernentes a formas adultas de espécies do subgênero Melanoconion. Assim é que, embora assinalada com maior frequiência e elevada densidade em meio florestal primitivo, Culex sacchettae Sirivanakarn e Jakob revelou capacidade de adaptação ao meio

\footnotetext{
* Realizado com auxílio financeiro da Fundação de Amparo à Pesquisa do Estado de São Paulo-FAPESP (Proc. $n^{9}$ 89/0486-0).

** Departamento de Epidemiologia da Faculdade de Saúde Pública da Universidade de São Paulo - São Paulo, SP . Brasil.
}

Separatas/Reprints: O.P. Forattini - Av. Dr. Amaldo, 715 01255 - São Paulo, SP - Brasil.

Publicação financiada pela FAPESP. Processo Medicina 90/ 4602-1. ambiente modificado, principalmente mediante alteração de comportamento. Por sua vez, para $C x$. ribeirensis Forattini e Sallum, detectou-se evidências de nítido favorecimento, por parte da atividade antrópica, resultando em significante presença desse mosquito em áreas artificialmente abertas (Forattini e col. ${ }^{4}, 1986$; Forattini e Gomes ${ }^{6}, 1988$ ).

A presença de Culex (Mel.) delpontei Duret, na região meridional do Brasil, correspondente à área do Vale do Ribeira, Estado de São Paulo, despertou interesse por maiores informaçð̃es a respeito da biologia e identificação desse mosquito (Forattini e Sallum $\left.^{8}, 1989\right)$. E isso porque, tendo sido inicialmente assinalado no Paraguai e no norte da Argentina, pôde-se dele isolar várias cepas de arbovírus, incluindo diversas concernentes ao complexo da encefalite eqüina venezuelana. Tais achados fizeram com que se levantasse a hipótese de seu possivel papel de vetor enzoótico desses agentes virais. Acresce o ter sido registrado significante desproporção entre o número de isolamentos e o de espécimes testados, ou seja, 18 de 40 no Chaco e 5 
de 16 em Santa Fé, Argentina. Isso também levou à suposição da existência de provável mecanismo de transmissão transovariana, nessa espécie de culicídeo (Mitchell e col. ${ }^{11,12}, 1985,1987$ ).

Face a tais dados, teve-se por oportuna a realização de observaçōes que permitissem a aquisição de novos conhecimentos sobre a biologia de populaçōes de representantes do subgênero, e presentes na mesma área, cujos resultados estão descritos no presente trabalho.

\section{Material e Método}

As observações foram levadas a efeito na localidade denominada de Sítio Palmeira, situada nos arredores da cidade de Iguape, Estado de São Paulo, às margens da rodovia que liga esse município ao de Biguá, e do rio Peropava, afluente do Ribeira. A sua situação corresponde a $24^{\circ} 37^{\prime}$ de latitude sul e $47^{\circ} 31^{\prime}$ de longitude oeste.

A área caracteriza-se como ambiente antrópico acentuadamente alterado, para o exercício de atividades agrícolas, ali representadas por variados tipos de plantações de pequena e de média extensão, sobressaindo as de arroz, cebola e frutas. $O$ rio Peropava constitui curso de volume médio e, como aspecto frequiente, apresenta a superficie coberta por vegetação aquática constituída por vários tipos de vegetais. Contudo, os representantes de Pistia des- tacam-se pela sua abundância, formando às vezes verdadeiros "tapetes" que se acumulam principalmente nos remansos (Fig. 1).

As atividades consistiram em coletas regulares de mosquitos adultos e, de maneira aleatória embora sistemática, de formas imaturas. Assim procedendo, objetivou-se observar o comportamento daqueles, enquanto que para as formas imaturas limitou-se ao encontro dos criadouros, os quais, pelos dados disponiveis, são ainda escassamente conhecidos. Essas atividades tiveram seu início em fevereiro de 1989 e se prolongaram até março de 1990 , inclusive.

As coletas de adultos obedeceram a ritmo mensal, totalizando 14 capturas regularmente efetuadas ao longo do supracitado período. Foram empregadas técnicas baseadas no uso de isca humana (IH) e de armadilhas (CDC) tipo miniatura, iscadas com $\mathrm{CO}_{2}$ (Forattini e col. 5 , 1987). Considerando-se as características da área, representadas na Fig. 2, e que incluem casas de residência, campos de cultivos e vegetação secundária tipo capoeira, foram estabelecidos os seguintes locais de coleta:

a) no peridomicílio de uma das residências ali existentes, a isca humana (IH) e uma armadilha (CDC1). Ambos esses pontos de captura separados por distância correspondente a cerca de $50 \mathrm{~m}$;

b) em campo aberto de cultivo e uma armadilha (CDC-2), distante cerca de 100m da casa, em linha reta;

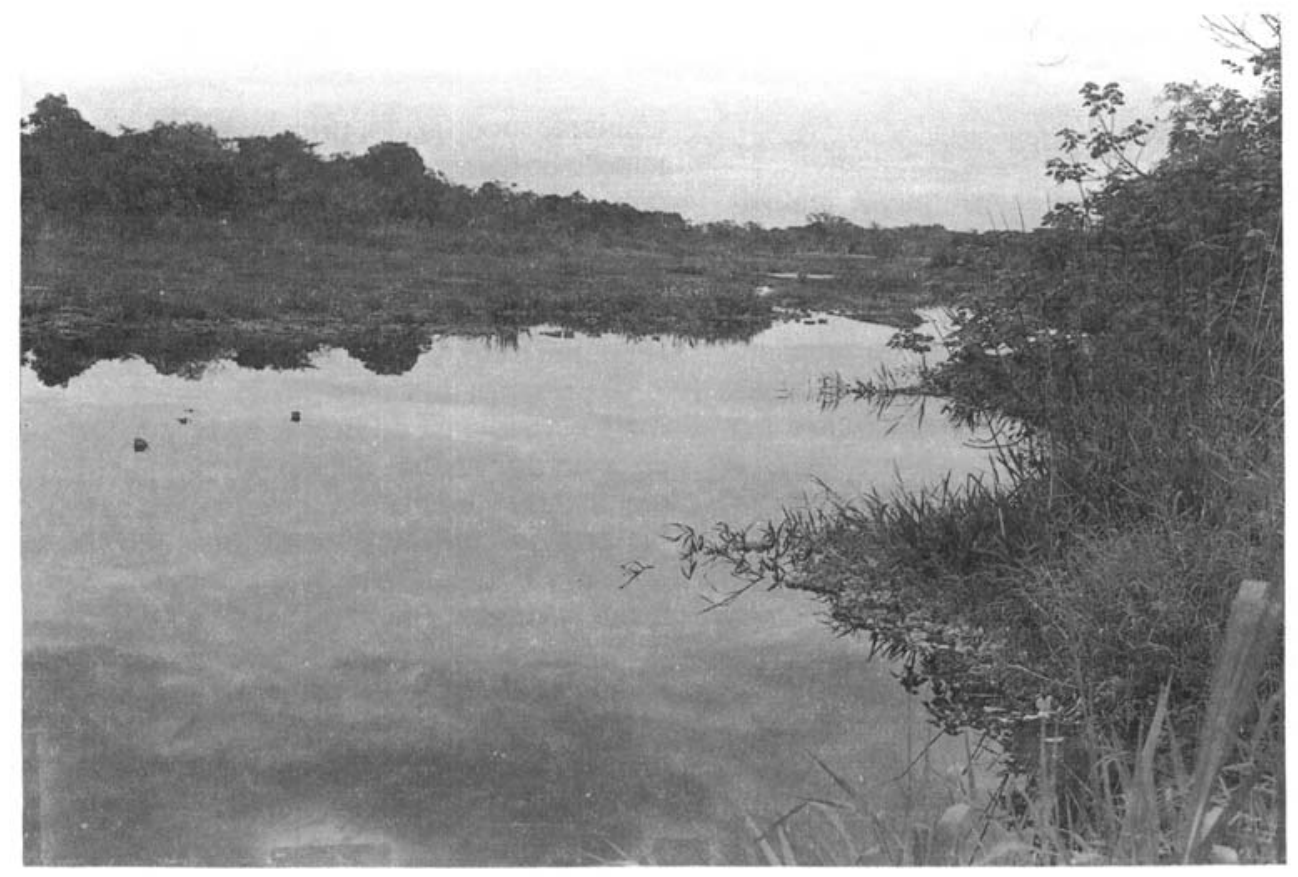

Figura 1 . Aspecto do rio Peropava, Iguape, Estado de São Paulo, notando-se a cobertura da superfície por vegetação aquática, com abundância de representantes de Pistia. 


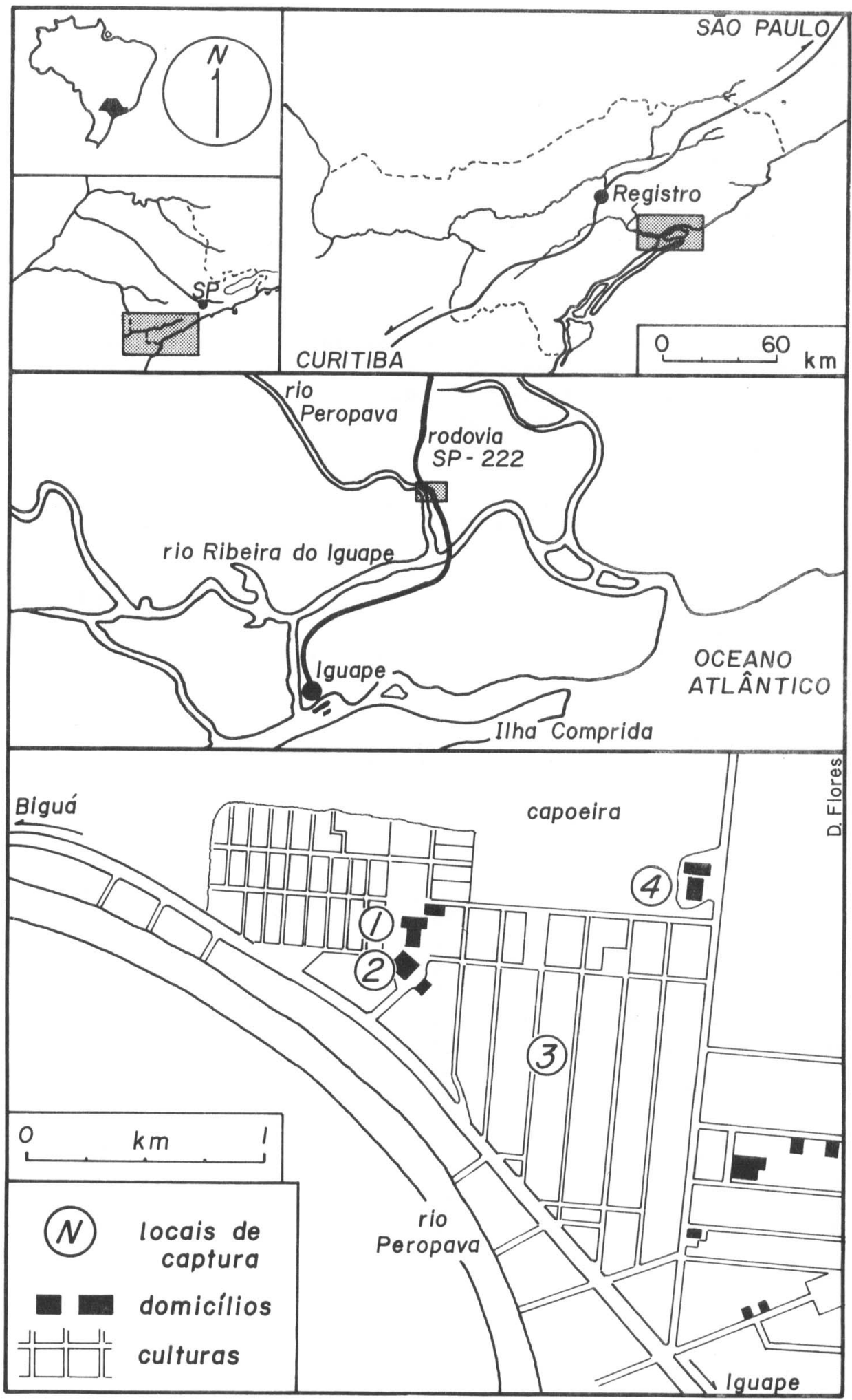

Figura 2. Esquemas da área trabalhada, mostrando a localızação dos pontos de coleta:

1 - isca humana $(\mathrm{IH})$, no peridomicílio.

2 - armadilha CDC-1, no peridomicilio.

3 - armadilha CDC-2, no campo aberto e cultivado.

4 - armadilha CDC-3, na vegetação tipo capoeira. 
c) em vegetação tipo capoeira e uma armadilha (CDC-3), distante cerca de $200 \mathrm{~m}$ da casa, em linha reta.

Assim pois, essas quatro coletas foram levadas a efeito de maneira simultânea, obedecendo a horários, das 16:00 às 0:07 h para a IH e das 18:00 às 0:06 para as CDC. No caso da IH e da CDC-1, o número dos espécimes coletados foi computado para cada intervalo de uma hora. Para as outras $\mathrm{CDC}$, levou-se em conta somente o total de exemplares capturados.

Como o tempo dispendido nestas observações restringiu-se a 14 meses, os resultados obtidos são expressos como médias horárias $(m h)$, isto é, dividindo-se o número de espécimes obtidos pelo produto resultante do número de horas trabalhadas multiplicado pelo de homens empregados na coleta, e que foi sempre de dois. Obviamente, para o caso das armadilhas automáticas, esse denominador corresponde somente ao número de horas em que 0 aparelho operou.

As observações concernentes às formas imaturas também tiveram ritmo mensal, embora sem outras finalidades que não a de simplesmente identificar os criadouros. Apesar dos dados disponíveis serem escassos, os encontros de Peyton e Wilkerson*, em janeiro de 1989, na mesma região, fizeram com que as coletas se concentrassem no referido rio Peropava e cursos próximos.

\section{Resultados}

\section{Coleta de adultos}

No período mencionado, foram coletados 76.950 mosquitos, dos quais, 17.024 eram espécimens femininos de Culex (Melanoconion). Destes, $16.427(96,5 \%)$ foram representados pelas seguintes espécies:

\begin{tabular}{lcr} 
& $\mathrm{n}$ & $\%$ \\
Cx. delpontei & 2.376 & 14,5 \\
Cx. ocossa & 6.088 & 37,1 \\
Cx. ribeirensis & 4.162 & 25,3 \\
Cx. sacchettae & 2.646 & 16,1 \\
Cx. taeniopus & 1.155 & 7,0 \\
Total & & \\
\cline { 2 - 3 } & 16.427 & 100,0
\end{tabular}

Os restantes que, em conjunto, constituíram

Tabela 1 . Resultados, por tipo e local de coleta, relativos às espécies menos freqüentes, do subgênero Melanoconion, no Sítio Palmeira, Município de Iguape, SP (fevereiro de 1989 a março de 1990).

\begin{tabular}{|c|c|c|c|c|c|c|c|c|c|c|}
\hline \multirow{2}{*}{$\begin{array}{c}\text { Espécies } \\
e \\
\text { Grupos }\end{array}$} & \multicolumn{2}{|c|}{ IH } & \multicolumn{2}{|c|}{ CDC-1 } & \multicolumn{2}{|c|}{$C D C-2$} & \multicolumn{2}{|c|}{ CDC-3 } & \multicolumn{2}{|c|}{ TOTAL } \\
\hline & $n$ & $\%$ & $n$ & $\%$ & $n$ & $\%$ & $n$ & $\%$ & $n$ & $\%$ \\
\hline Culex educator" & 20 & 18,3 & 67 & 36,8 & 7 & 10,3 & 21 & 8,8 & 115 & 19,2 \\
\hline Cx. ensiformis & 4 & 3,7 & - & - & - & - & - & - & 4 & 0,7 \\
\hline Cx. evansae & - & - & 1 & 0,6 & - & - & 10 & 4,2 & 11 & 1,8 \\
\hline Grupo Atratus & - & - & 2 & 1,1 & - & - & - & - & 2 & 0,3 \\
\hline Gr. Pilosus & 76 & 69,7 & 25 & 13,7 & 13 & 19,1 & 33 & 13,8 & 147 & 24,6 \\
\hline Cx. inadimirabilis & - & - & 4 & 2,2 & - & - & 5 & 2,1 & 9 & 1,5 \\
\hline Cx. intrincatus & - & - & - & - & 2 & 2,9 & - & - & 2 & 0,3 \\
\hline Cx. lopesi & - & - & - & - & 2 & 2,9 & 3 & 1,3 & 5 & 0,9 \\
\hline Cx. pedroi & - & - & 4 & 2,2 & - & - & - & - & 4 & 0,7 \\
\hline Cx. pereyrai & 2 & 1,8 & 5 & 2,7 & - & - & 2 & 0,8 & 9 & 1,5 \\
\hline Cx. plectoporpe & 4 & 3,7 & 2 & 1,1 & 6 & 8,8 & 4 & 1,7 & 16 & 2,7 \\
\hline CX. $(M e l$.$) sp.$ & 1 & 0,9 & 36 & 19,8 & 16 & 23,6 & 17 & 7,1 & 70 & 11,7 \\
\hline Cx. spissipes & 1 & 0,9 & 36 & 19,8 & 20 & 29,4 & 144 & 60,2 & 201 & 33,6 \\
\hline Cx. zeteky & 1 & 0,9 & - & - & 2 & 2,9 & - & - & 3 & 0,5 \\
\hline TOTAL & 109 & 99,9 & 100,0 & 182 & 68 & 99,9 & 239 & 100,0 & 598 & 100,0 \\
\hline
\end{tabular}

$\%$ - sobre os totais gerais respectivos

$\mathrm{CDC}$ - armadilha automática miniatura, com isca de $\mathrm{CO}^{2}$

IH - isca humana

- próximo

* E.L. Peyton e R.C. Wilkerson - comunicação pessoal. 


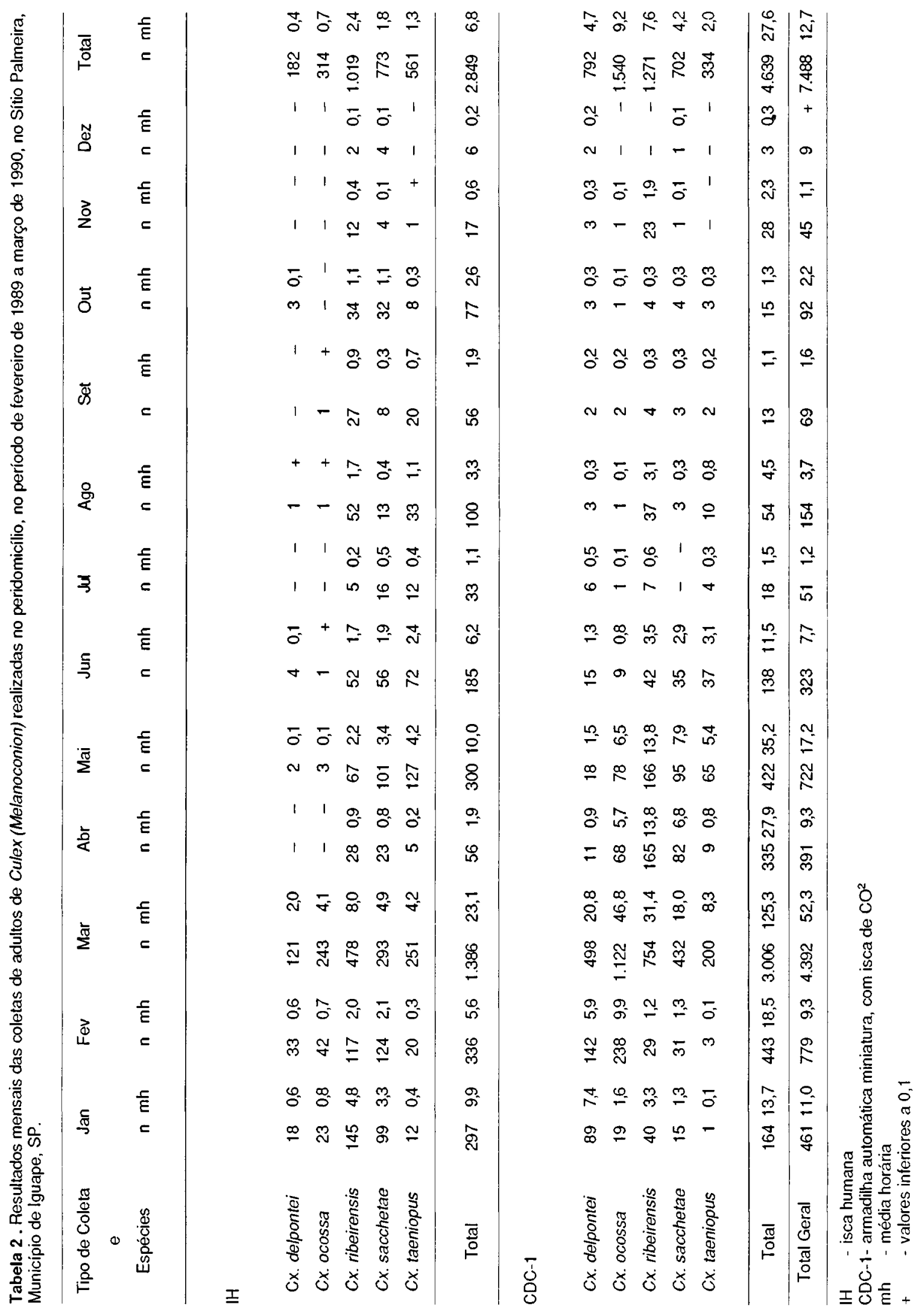


3,5\% das coletas desse grupo, compareceram como consta da Tabela 1 . Em vista desses resultados, os dados apresentados a seguir referem-se às cinco espécies supramencionadas.

Peridomicilio - Como se referiu, as coletas peridomiciliares foram levadas a efeito com emprego da isca humana (IH) e de uma das armadilhas automáticas miniaturas (CDC-1). Os resultados obtidos podem ser vistos na Tabela 2 , onde se observa que a frequiência dessas espécies a esse ambiente concentra-se no primeiro trimestre do ano. Verifica-se, nesse sentido, maior regularidade no que concerne à presença de $C x$. ribeirensis e $C x$. sacchettae, ao longo de todo o período anual. $\grave{A}$ constância do comparecimento desses dois mosquitos, acrescenta-se os valores globais das respectivas médias horárias $(m h)$, de 2,4 e 1,5 para IH e de 8,4 e 5,8 para $C D C-1$, e que, somados à supracitada freqüência, destacam-se dos correspondentes aos demais representantes. Considerando-se os resultados concernentes ao mencionado primeiro trimestre, observou-se que, para a $\mathrm{IH}$, o rendimento referente à soma das $m h$ dos meses de janeiro, fevereiro a março foi, em ordem decrescente, o seguinte:

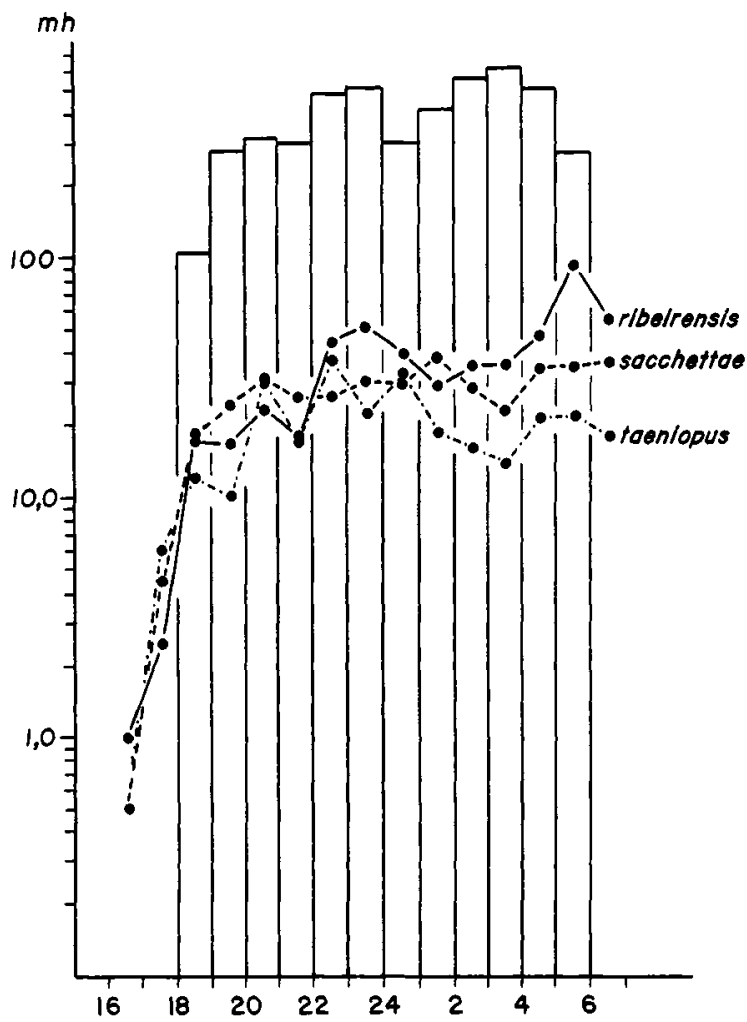

\begin{tabular}{|c|c|}
\hline & $\mathrm{n}$ \\
\hline$C x$. ribeirensis & 740 \\
\hline Cx. sacchettae & 516 \\
\hline$C x$. ocossa & 308 \\
\hline Cx. taeniopus & 283 \\
\hline$C x$. delpontei & 172 \\
\hline al & 010 \\
\hline
\end{tabular}

No atinente às coletas com CDC-1, para o mesmo período, o rendimento obtido foi o que segue, também por ordem decrescente:

\begin{tabular}{|c|c|c|}
\hline & $\mathrm{n}$ & $\mathrm{ml}$ \\
\hline$C x . o c o s s a$ & 1.839 & 30,6 \\
\hline Cx. sacchettae & 798 & 13,3 \\
\hline Cx. delpontei & 787 & 13,1 \\
\hline Cx. sacchettae & 562 & 9,4 \\
\hline Cx. taeniopus & 60 & 1,0 \\
\hline Total & 4.046 & 67,4 \\
\hline
\end{tabular}

Observou-se assim, que a simples presença no peridomicílio, por parte das cinco espécies, não correspondeu, em igual medida, à atração pela $\mathrm{IH}$. Alguma concordância, nesse sentido, foi possível

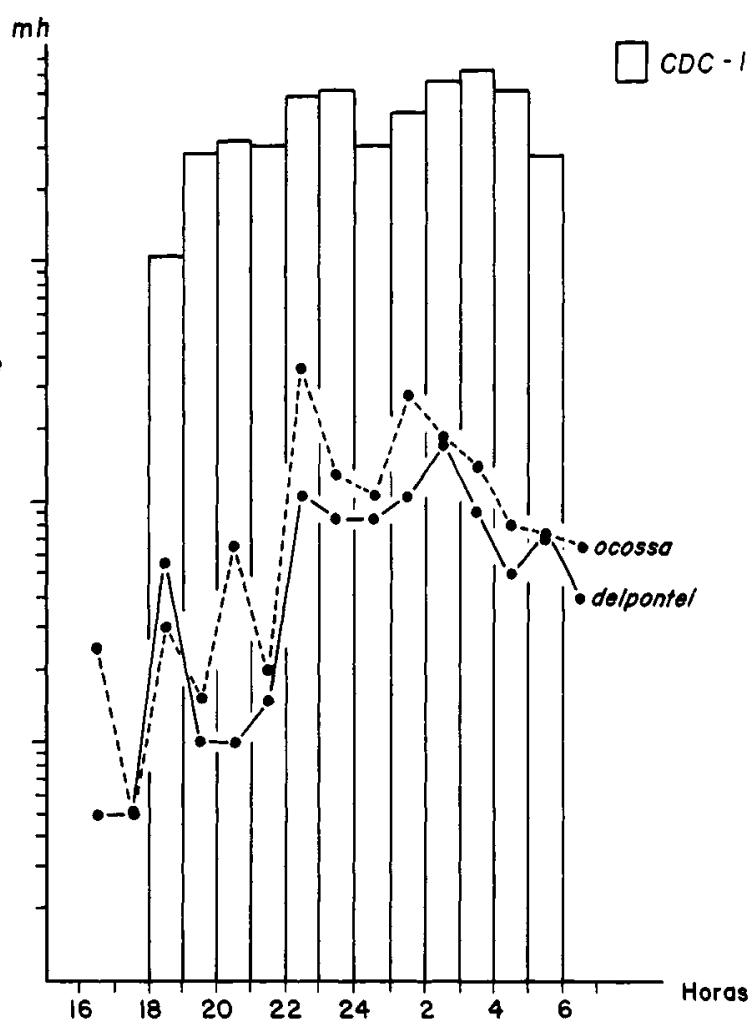

Figura 3. Freqüência das médias horárias $(\mathrm{mh})$, obtidas com a isca humana, e das coletas concomitantes com armadilhas automáticas (CDC-1), para as cinco espécies de Culex (Melanoconion). 


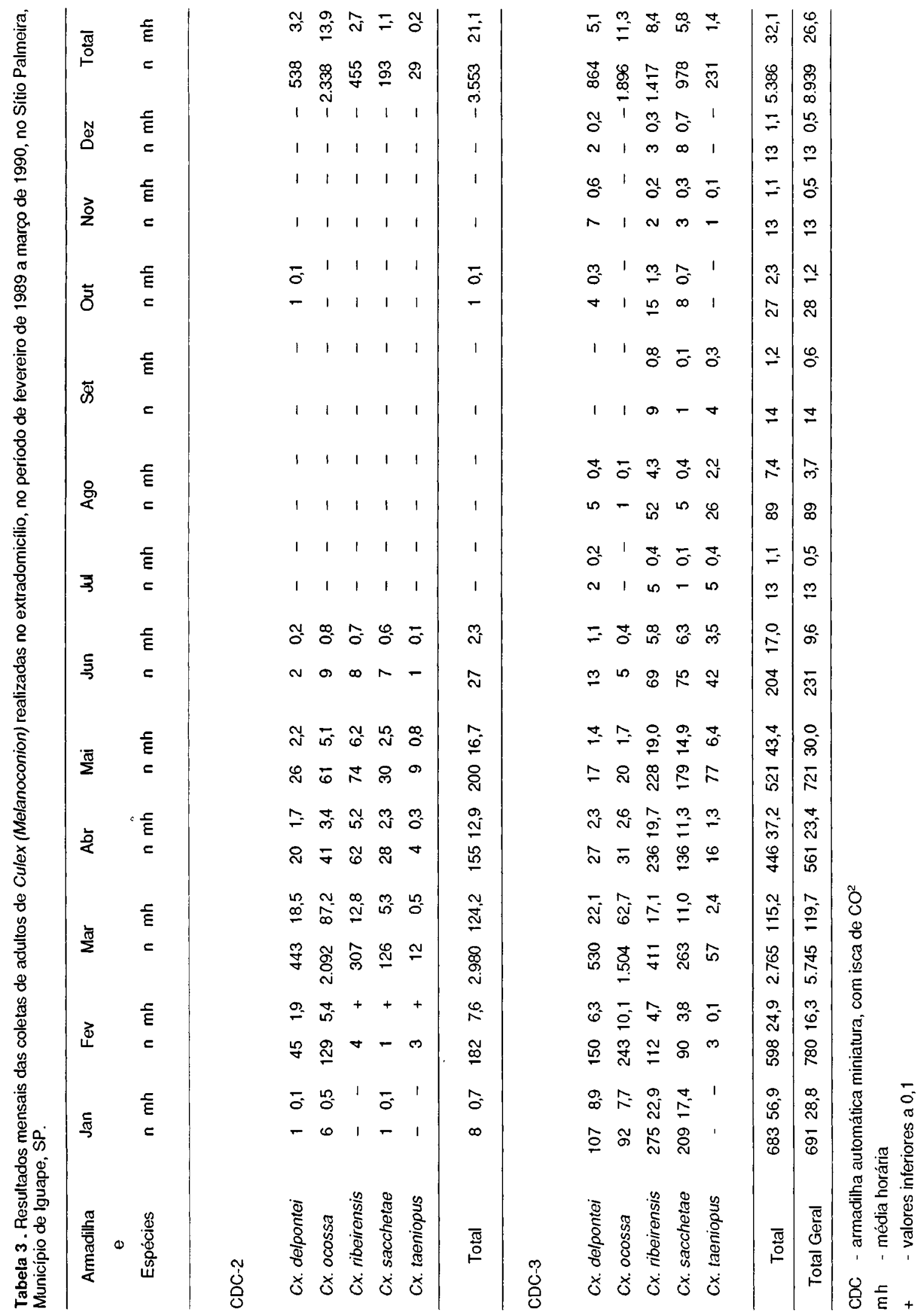


detectar em $C x$. ribeirensis, e mesmo em $C x$. sacchettae, ambos apresentando maior procura dessa fonte sanguiinea. Quanto a $C x$. delpontei, embora comparecendo ao ambiente com certa freqüência, seu rendimento na IH foi menor de todos.

Dentro do caráter essencialmente noturno das atividades desses mosquitos, pôde-se registrar a frequiência horária, como apresentada nos gráficos da Fig. 3. Assim, ao lado dos resultados globais obtidos com a armadilha CDC-1, verificou-se que o comparecimento horário à $\mathrm{IH}$, em uma primeira tentativa, pode ser considerado como tendo sido de dois tipos. O primeiro, revelado por $C x$. ribeirensis, $C x$. sacchettae e $C x$. taeniopus, mostra elevação mais rápida dessa atividade, logo no início da noite, e com tendência a se manter durante todo o período noturno. O segundo, evidenciado por $C x$. delponte $i$ e $C x$. ocossa, exibe incremento mais lento, atingindo seus valores máximos no meio do período, tendendo a cair mais significativamente após três horas, e que imediatamente antecedem e se seguem à meia-noite.

Extradomicílio - A Tabela 3 apresenta os resultados conseguidos com as armadilhas automáticas CDC-2 e CDC-3. Verificou-se também maior rendimento correspondente ao primeiro trimestre do ano, sobretudo ao mês de março. $E$ isso, tanto em área aberta (CDC-2) como em vegetação tipo capoeira (CDC-3). Observou-se concordância desses resultados com os obtidos na IH e na CDC-1, relatados nos parágrafos anteriores. Obteve-se também maior regularidade de comparecimento de mosquitos na capoeira, principalmente em relação a $C x$. ribeirensis e $C x$. sacchettae e, de maneira menos marcada, também por parte de $C x$. delpontei.

\section{Coleta de formas imaturas}

A pesquisa de criadouros dessas espécies possibilitou o encontro dos correspondentes a $C x$. delpontei e $C x$. ocossa. Os achados foram feitos em cursos de água de apreciável profundidade, representados localmente pelos rios Peropava e Ribeira. As formas imaturas foram coletadas em associação com a vegetação aquática, principalmente Pistia, a qual, em algumas ocasiões, chegam a formar extensas coberturas superficiais, concentradas nos remansos e nas margens dessas coleções líquidas (Fig. 1). Os resultados globais dessas coletas de larvas e pupas foram representados por 452 espécimens de $C x$. delpontei e 233 de $C x$. ocossa, dos quais foi possível obter, no laboratório, respectivamente 311 e 173 exemplares adultos de ambos os sexos.

\section{Discussăo}

Os resultados aqui relatados trazem novos aportes a respeito das possíveis tendências à domi- ciliação, por parte de representantes de Culex (Melanoconion). Assim é que, em primeiro lugar, a freqüência ao peridomicílio e ao ambiente resultante das modificaçőes de origem antrópica, por parte de $C x$. ribeirensis, obteve confirmação no que concerne a observações feitas anteriormente (Forattini e col${ }^{4} ., 1986$; Forattini e Gomes ${ }^{6}, 1988$ ). Quanto a $C x$. sacchettae, sua capacidade de domiciliação foi inicialmente detectada em áreas próximas e adjacentes ao meio natural primitivo, representado pela floresta tropical atlântica da planície (Forattini e col. $\left.{ }^{9}, 1990\right)$. No entanto, as presentes observações permitiram evidenciar a possibilidade de ocorrência de fenômeno análogo, em ambiente antrópico acentuadamente alterado e apreciavelmente afastado do meio florestal primitivo. Verificando-se os resultados obtidos no peridomicílio e correspondentes ao mês de março, como periodo de maior produção, observa-se que, para as coletas com $\mathrm{IH}$, a $m h$ de 4,9 foi bastante próxima, ou mesmo comparável com a $m h$ de 5,2 , registrada no mesmo ambiente, nas supracitadas investigaçð̃es.

Diante disso, é de se admitir a hipótese de, ao menos na região estudada, a população de $C x$. sacchettae, embora predominante no ambiente primitivo natural, compartilha com $C x$. ribeirensis a tendência à domiciliação. Assim pois, ao se computar o total de coletas peri e extradomiciliares (Tabelas $2 \mathrm{e}$ 3 ), essas duas espécies, e que foram as que se apresentaram com maior regularidade ao longo do ano, tiveram a maioria dos seus exemplares coletados no peridomicílio. Mais exatamente, $55,0 \%$ para $C x$. ribeirensis e 55,7\% para $C x$. sacchettae. Esse paralelismo se mantém, ao se considerar os resultados referentes ao período de maior rendimento da captura, e que foi o mês de março. Nessa ocasião, os percentuais correspondentes aos espécimens coletados no peridomicílio (IH e CDC-1) foram de 63,2 e de 65,0 , respectivamente. Pôde-se assim constatar o possivel papel do domicílio humano, como fator local de atração para essas duas espécies de mosquitos, uma vez que a maioria dos seus espécimens foi obtida nesse meio. Em relação a $C x$. ribeirensis, em observações anteriores já se obteve evidências nesse sentido (Forattini e col. ${ }^{7}, 1989$ ). O mesmo porém não se pode dizer de $C x$. delpontei $C x$. ocossa, com percentuais respectivos de 41,0 e de 30,5 coletados no ambiente domiciliar, e repetindo-se em março, quando essas cifras foram de 38,9 e 27,4. No que tange a $C x$. taeniopus, seu desempenho de maior consistência foi o referente à freqüência na IH onde, no mês de março, atingiu a $m h$ de 4,2 e, nesse mesmo período, apresentou $86,7 \%$ dos seus espécimens obtidos no peridomicílio.

Considerando-se apenas os resultados das capturas peridomiciliares (IH e CDC-1) constantes da Tabcla 2, os percentuais de comparecimento à isca 
humana (IH), tanto de maneira global como no mês de março, foram os seguintes:

$\begin{array}{lcc} & \text { Global } & \text { Março } \\ \text { Cx. delpontei } & 18,7 & 19,5 \\ \text { Cx. ocossa } & 16,9 & 17,8 \\ \text { Cx. ribeirensis } & 44,5 & 38,8 \\ \text { Cx. sacchettae } & 52,4 & 40,4 \\ \text { Cx. taeniopus } & 62,7 & 55,6\end{array}$

Pode-se assim verificar que a procura do homem como fonte para o exercício da hematofagia foi sensivelmente menor por parte de $C x$. delponte $i$ e $C x$. ocossa, em comparação com a das outras três espécies. Tais feições parecem confirmar a hipótese da existência de possível capacidade de domiciliação de $C x$. ribeirensis e $C x$. sacchettae os quais, nessa região, aliaram aos caracteres supramencionados o aspecto de maior persistência em suas atividades, ao longo do período gasto nas presentes observações.

Embora tais resultados com a IH não indiquem necessariamente o grau de antropofilia, senso estrito, como seria o caso da identificação do sangue ingerido, não deixam de se revestir de aspecto bastante sugestivo. Com relação a $C x$. ribeirensis e $C x$. sacchettae, já se teve oportunidade anterior de assinalar o comparecimento às coletas com essa isca, bem como alguma positividade para sangue humano (Forattini e col. $5,7,1987,1989)$. No que concerne a $C x$. delpontei, pôde-se adquirir idéia mais colsistente, do que os dados até agora disponiveis, sobre a sua presença como possível resultado da atração exercida por essa fonte sangüínea. Em observações levadas a efeito na região norte da Argentina, essa espécie foi capturada com isca de ave e, em alguns espécimens, a identificação do sangue ingerido revelou variedade apreciável de hospedeiros (Mitchell e col. $\left.{ }^{10,11}, 1985,1987\right)$. De qualquer maneira, esse culicídeo possui certo grau de frequiência ao ambiente domiciliar e de atração pelo homem, embora, ao que parece, em nível bastante inferior ao apresentado pelas duas espécies supracitadas. Quanto a $C x$. ocossa, o comportamento que foi detectado assemelha-se ao de $C x$. delpontei, porém de feição bem menos regular, uma vez que sua presença concentra-se mais significativamente no primeiro trimestre do ano, em especial modo no mês de março. Em relação a $C x$. taeniopus, têm sido realizadas observações em algumas outras regiões neotropicais, como Trinidad e Guatemala, ocasião em que foram obtidas evidências a respeito de sua atração por ampla gama de hospedeiros, como marsupiais (Didelphis), pequenos mamíferos, aves e, mais raramente, répteis, além de ter sido encontrado em ambiente domiciliar (Davies $^{3}, 1978$; Cupp e col. ${ }^{1}$, 1986). Evidentemente, não se trata de transportar, de início, tais evidências para as observações aqui relatadas, eis que estas, tendo sido realizadas em região distinta como a do sudeste do Brasil, referem-se a população que, embora em princípio identificada a $C x$. taeniopus, pode, na realidade, representar outro conjunto populacional diferente daquele que foi objeto das observações supracitadas. De qualquer maneira, mesmo sem apresentar comportamento muito regular, esse mosquito revelou apreciável atração pelo meio domiciliar e compareceu às coletas com IH.

O período noturno, no qual foram levadas a efeito as coletas, permitiu a obtenção de perfis das atividades, como mostram os gráficos da Fig. 3. Em relação a $C x$. ribeirensis, houve concordância com o que já se observou em outra oportunidade (Forattini e Gomes ${ }^{6}, 1988$ ). A esse tipo de comportamento assemelhou-se o apresentado por $C x$. sacchettae e $C x$. taeniopus. Este último já tinha revelado apreciável atividade crepuscular, prolongada pelo período noturno, sofrendo alguma influência da iluminação propiciada pelo luar (Davies ${ }^{2}$, 1975; Cupp e col. ${ }^{1}$, 1986). Quanto a $C x$. delpontei e Cx. ocossa, as observaçōes indicaram maior atividade após a instalação do período noturno, atingindo o máximo algumas horas antes da meia-noite e passando a declinar algumas horas depois. Se esses dois tipos de comportamento indicam populações distintas ou o resultado da atuação de fatores ambientais, é assunto que requer maiores investigações.

No que tange aos locais de criação, pôde-se identificar os concernentes a $C x$. delpontei, representados por cursos de água de média ou grande envergadura, mas em locais com abundante vegetação aquática flutuante, principalmente representada por Pistia. Tais achados concordam com o aspecto geral dos locais onde, na Argentina, se assimilou à presença de adultos da espécie (Sebattini e col. $\left.{ }^{13}, 1985\right)$. Diante disso, é de se levantar a hipótese de tal associação com vegetais aquáticos flutuantes poder propiciar às formas imaturas suficiente proteção e abrigo que lhes impeça de mergulharem águas profundas, de onde dificilmente poderiam retomar à superfície.

Concluindo, é possível considerar que existem evidências indicadoras de tendências à domiciliação por parte de $C x$. ribeirensis e $C x$. Sacchettae. Em relação à primeira, as presentes observações vieram confirmar o que já se tinha constatado em publicaçð̋es anteriores. Quanto à segunda espécie, tal tendência foi mais recentemente entrevista, e as pesquisas aqui relatadas vieram dar maior consistência à hipótese (Forattini e col. ${ }^{9}, 1990$ ). Quanto aos outros representantes aqui tratados, ao que tudo indica, a propensão para se domiciliarem não se manifestou, embora alguns deles, especialmente $C x$. delpontei, possa ser encontrado com certa frequiência no meio domiciliar. 
Diante disso, considerando-se o papel desses mosquitos como vetores de enzootias silvestres, aventa-se a possibilidade de algumas dessas espécies poderem introduzir agentes, como arbovírus, no ambiente antrópico, mesmo altamente modificado.

FORATTINI, O.P. et al. [Domiciliation of Culex (Melanoconion) mosquitoes in man-made deeply modified environment] Rev. Saúde públ., S. Paulo, 25: 257-66, 1991. Some data on Culex (Melanoconion) mosquito behavior in human environments are presented. Adults were collected simultaneously through peridomiciliary and extradomiciliary catches, with the use of human bait inclusive. Dominant species were identified as $C x$. delpontei, $C x$. ocossa, $C x$. ribeirensis, $C x$. sacchettae and $C x$. taeniopus. In the domiciliary environment $C x$. ribeirensis and $C x$. sacchettae, the principal species found, were collected with considerables frequency by the use of human bait placed in the peridomiciliar environment. $C x$. delpontei and $C x$. ocossa showed a lower frequency in that environment. Greater numbers of adults were obtained in the first three months of the year, particularly in March. Nocturnal activities showed two apparently distincts patterns. One of them was presented by $C x$. ribeirensis, $C x$. sacchetlae and $C x$. taeniopus as a curve increasing quickly during the first hours os the night and mantaining the same level until dawn. The other was shown by $C x$. delpontei and $C x$. ocossa, as a curve which increased gradually until midnight, and then decreased gradual by until dawn. Breeding places of $C x$. delpontei were found in medium and large rivers with a covering of aquating floating vegetation, mainly Pistia. Considerations relating to those ecological aspects of epidemiological interest are made.

Keywords: Mosquitoes. Culex (Melanoconion). Culex ribeirensis. Culex sacchettae. Culex delpontei. Culex taeniopus. Domiciliation.

\section{Referências Bibliográficas}

1. CUPP, E.W.; SCHERER, W.F.; LOK, J.B.; BRENNER, R.J.; DZIEM, G.M.; ORDONEZ, J.V. Entomological studies at an enzootic Venezuelan equine encephalitis virus focus in Guatemala, 1977-1980. Amer. J. trop. Med. Hyg., 35: 851-9, 1986.

2. DAVIES, J.B. Moonlight and the biting activity of Culex (Melanoconion) portesi Senevet \& Abonnenc and $C$. (M.) taeniopus D. \& K. (Diptera: Culicidae) in Trinidad forests. Bull. ent. Res., 65: 81-96, 1975.

3. DAVIES, J.B. Attraction of Culex portesi Senevet \& Abonnenc and Culex taeniopus Dyar \& Knab (Diptera: Cu- licidae) to 20 species exposed in a Trinidad forest. IBaits ranked by numbers of mosquitoes caught and engorged. Bull. ent. Res., 68: 707-19, 1978.

4. FORATTINI, O.P.; GOMES, A. de C.; NATAL, D.; SANTOS, J.L.F. Observaçōes sobre atividades de mosquitos Culicidae em matas primitivas da planície e perfis epidemiológicos de vários ambientes no Vale do Ribeira, São Pau1o, Brasil. Rev. Saúde públ. , S.Paulo, 20: 178-203, 1986.

5. FORATTINI, O.P.; GOMES, A. de C.; NATAL, D.; KAKITANI, I.; MARUCCI, D. Preferências alimentares de mosquitos Culicidae no Vale do Ribeira, São Paulo, Brasil. Rev. Saúde públ., S. Paulo, 21: 171-87, 1987.

6. FORATTINI, O.P. \& GOMES, A. de C. Biting activity pattems of Culex (Melanoconion) ribeirensis in southem Brazil. J. Amer. Mosq. Control Ass., 4: 175-8, 1988.

7. FORATTINI, O. P. \& SALLUM, M.A.M. Redescription of Culex (Melanoconion) delpontei Duret, 1968 and $C x$. (Mel.) pereyrai Duret, 1967, from southern Brazil. Proc. ent. Soc. Washington, 91: 473-85, 1989.

8. FORATTINI, O.P.; GOMES, A. de C.; NATAL, D.; KAKITANI, I.; MARUCCI, D. Preferências alimentares e domiciliação de mosquitos Culicidae no Vale do Ribeira, São Paulo, Brasil, com especial referência a Aedes scapularis e a Culex (Melanoconion). Rev. Saúde públ., S. Paulo, 23: 9-19, 1989.

9. FORATTINI, O.P.; GOMES, A. de C.; SANTOS, J.L.F.; KAKITANI, I; MARUCCI, D. Freqüência ao ambiente humano e dispersão de mosquitos Culicidae em área adjacente à mata atlântica primitiva da planície. Rev. Saúde públ., S. Paulo, 24: 101-7, 1990.

10. MITCHELL, C.J.; MONATH ,T.P.; SABATTINI, M.S.; CROPP, C.B.; DAFFNER, J.F.; CALISHER, C.H.; JAKOB, W.L.; CHRISTENSEN, H.A. Arbovirus investigations in Argentina, 1977-1980. II Arthropod collections and virus isolations from argentine mosquitoes. Amer. J. trop. Med. Hyg., 34: 945-55, 1985.

11. MTTCHELL, C.J.; MONATH, T.P.; SABATTIN, M.S.; CHRISTENSEN, H.A.; DARSIE Jr., R.F.; JAKOB, W.L.; DAFFNER, J.P. Host-feeding patterns of Argentine mosquitoes (Diptera: Culicidae) collected during and after an epizootic of westem equine encephalitis. $J$. med. ent., 24: 260-7, 1987.

12. MITCHELL, C.J.; MONATH , T.P.; SABATTINI, M.S.; DAFFNER, J.F.; CROPP, C.B.; CALISHER, C.H.; DARSIE Jr., R.F.; JAKOB, W.L. Arbovirus isolations from mosquitoes collected during and after the 19821983 epizootic of western equine encephalitis in Argentina. Amer. J. trop. Med. Hyg., 36: 107-13, 1987.

13. SABATTINI, M.S.; MONATH , T.P.; MITCHELL, C.J.; DAFFNER, J.F.; BOWEN, G.S.; PAULI, R.; CONTIGIANI, M.S. Arbovirus investigations in Argentina, 1977-1980. I. Historical aspects and description of study sites. Amer.J. trop. Med. Hyg., 34: 937-44, 1985.

Recebido para publicaçăo em 22/04/1991 Aprovado para publicação em 18107/1991 